\title{
C14orf166 overexpression correlates with tumor progression and poor prognosis of breast cancer
}

Tuck-yun Cheang ${ }^{1 \dagger}$, Hong-yan Zhou ${ }^{2 \dagger}$, Wei Chen ${ }^{3 \dagger}$, Bing Zhang ${ }^{3}$, Liangshuai Liu ${ }^{3}$, Jianyong Yang ${ }^{3}$, Shenming Wang ${ }^{1 *}$ and Heping $\mathrm{Li}^{3,4^{*}}$

\begin{abstract}
Background: Chromosome 14 open reading frame 166 (C14orf166) is upregulated in various tumors, but its role in breast cancer has not been reported.

Methods: Quantitative real-time PCR and western blot were used to determine C14orf166 expression in normal breast epithelial cells (NBEC), breast cancer cells, and four matched pairs of breast cancer tissues and adjacent noncancerous tissues. Using immunohistochemistry, we determined C14orf166 expression in paraffin-embedded tissues from 121 breast cancer patients. Statistical analyses were performed to examine the associations among C14or166 expression, clinicopathological parameters and prognosis outcome of breast cancer. MTT and colony formation assay were used to determine the effect of C14orf166 on cell proliferation by overexpression or knockdown of C14orf166 level.

Results: C140rf166 was upregulated in breast cancer cell lines and tissues compared with the normal cells and adjacent normal breast tissues, high C140rf166 expression was positively with advancing clinical stage. The correlation analysis between C14orf166 expression and clinicopathological characteristics suggested C140rf166 expression was significantly correlated with clinical stages, T classification, N classification and PR expression, Kaplan-Meier curves with log rank tests showed patients with low C14orf166 expression had better survival, Cox-regression analysis suggested C14orf166 was an unfavorable prognostic factor for breast cancer patients. C140rf166 overexpression promoted breast cancer cell proliferation, whereas knockdown of C14orf166 inhibited this effect. Further analysis found C14orf166 overexpression inhibited cell cycle inhibitors P21 and P27 expression, and increased the levels of Cyclin D1 and phosphorylation of Rb, suggesting C14orf166 contributed to cell proliferation by regulating G1/S transition.
\end{abstract}

Conclusion: Our findings suggested C14orf166 could be a novel prognostic biomarker of breast cancer, it also contributes to cell proliferation by regulating $\mathrm{G} 1 / \mathrm{S}$ transition.

Keywords: Breast cancer, C14orf166, Prognostic factor, Cell proliferation

\section{Background}

Breast cancer is one of the leading causes of cancer death in women worldwide [1]. It is a heterogeneous tumor,

\footnotetext{
*Correspondence: pea33@163.com; drliheping@163.com

${ }^{\dagger}$ Tuck-yun Cheang, Hong-yan Zhou and Wei Chen are contributed equally to this work

1 Department of Thyroid and Breast Surgery, The First Affiliated Hospital of Sun Yat-sen University, 510080 Guangzhou, People's Republic of China ${ }^{4}$ Department of Medical Oncology, The First Affiliated Hospital of Sun Yat-sen University, 510080 Guangzhou, People's Republic of China Full list of author information is available at the end of the article
}

heterogeneity exists between and within subtypes of breast cancer cells [2]. The subtype of breast cancer can be divided based on the expression of estrogen receptor (ER), progesterone receptor (PR) and Her2 receptor tyrosine kinase (Her2). Thereinto,"triple negative" $\left(\mathrm{ER}^{-} /\right.$ $\mathrm{PR}^{-} /$Her2 ${ }^{-}$) breast cancer is the most aggressive and has poorest prognosis [3]. Some drugs have been used to treat breast cancer, for example, Sunitinib [4], Bevacizumab [5] and Trastuzumab [6]. But breast cancer have generated resistance to some drugs, for example, Her2 ${ }^{+}$ 
breast cancer have generated resistance to Trastumab [7]. The prevention and treatment are important for breast cancer, so it's essential to find novel prognostic factors and targets for breast cancer.

C14orf166 plays critical role in transcription initiation, HCV infection, RNA metabolism, and centrosome architecture. It can interact with PA subunit of influenza virus polymerase to activate some genes transcription and promote influenza virus replication [8]. Knockdown of C14orf166 suppresses the synthesis of about $50 \%$ RNA polymerase II transcripts, these suggest C14orf166 regulates gene transcription [9]. Junwei Lee and colleagues use proteomics approach find that C14orf166 also interacts with $\mathrm{HCV} 174$ which a mature hepatitis $C$ virus core protein, suggesting it may regulate $\mathrm{HCV}$ or cellular function during HCV infection [10]. C14orf166 interacts with DDX1, HSPC117 and FAM98B to form a complex to transport RNAs between the nucleus and the cytoplasm, suggesting it regulates the fate of RNA [11]. C14orf166 blocks the phosphorylation of ninein to regulation the function of ninein, ninein is required for the centrosome maturation, this suggests C14orf166 may participate in the centrosome architecture $[12,13]$.

C14orf166 is overexpressed in many tumors, such as pancreatic adenocarcinoma, brain tumor [13] and nasopharyngeal carcinoma. In nasopharyngeal carcinoma, C14or166 is overexpressed in nasopharyngeal carcinoma tissues, its expression is significantly correlated with gender, distant metastasis, vital status, $\mathrm{T}$ classification, $\mathrm{N}$ classification and clinical stage. It is an unfavorable prognostic factor for nasopharyngeal carcinoma patients [14]. In pancreatic adenocarcinoma, C14orf166 is overexpressed in the serum of patients with pancreatic adenocarcinoma detected by surface enhanced laser desorption/ionization time-of-flight mass spectrometry (SELDI-TOF-MS), and is a potential biomarker for pancreatic adenocarcinoma [15]. But the role of C14orf166 in breast cancer hasn't been studied.

Here, we determined C14orf166 expression in breast cancer cells and tissues used quantitative real-time PCR and western blot. Then we determined C14orf166 expression of a cohort of 121 breast cancer patients, and examined the relationship between C14orf166 expression and clinicopathological characteristic and clinical outcome. Finally, we determined the effect of C14orf166 on cell proliferation by modulating its expression. We found C14orf166 not only was a valuable prognostic factor for patients with breast cancer, but also promoted breast cancer proliferation.

\section{Methods}

\section{Human breast cancer tissue specimens}

Four fresh breast cancer tissues and their adjacent noncancerous breast tissues were obtained from the First
Affiliated Hospital, Sun Yat-Sen University, China, and frozen and stored in liquid nitrogen for further use. A cohort of 121 formalin-fixed and paraffin-embedded primary breast cancer samples also were obtained from the First Affiliated Hospital, Sun Yat-Sen University, China, from 2001 to 2008. All samples were confirmed by histological and clinical diagnosis. For the use of these clinical samples for research purposes, all samples obtained with written informed and approved by the Institutional Research Ethics Committee of the First Affiliated Hospital of Sun Yat-Sen University. The detailed clinical information about these samples is shown in Additional file 1: Table S1. The clinical stages of all the patients were classified according to the 2002 TNM staging of UICC (International Union against Cancer).

\section{Cell culture and transfection}

Normal human breast epithelial cells (NBEC) were cultured in Keratinocyte serum-free medium (Life Technologies) supplemented with epithelial growth factor, bovine pituitary extract. Breast cancer cell lines including MCF7, ZR-75-1, T47D, BT549, SKBR3, BT-474, MDA-MB231 and MDA-MB-361 were purchased from American Type Culture Collection and were cultured under conditions specified by the manufacturer.

The CDS sequence of C14orf166 was PCR amplified from cDNA of NBEC and cloned into the pMSCV-puro retroviral vector (indicated as C14orf166), the empty vector was used as negative control (indicated as Vector). Lipofectamine 2000 was used to transfected vectors into the indicated cells according to the manufacturer's instruction. The same cells transfected empty vector were used as the negative control.

The C14orf166 siRNA (indicated as C14orf166/RNAi) and its cognate control siRNA (indicated as Scramble) were obtained from Guangzhou RiboBio Co (Guangdong, China). $20 \mathrm{nM}$ siRNA were transfected into the indicated cells in six plates using Lipofectamine RNAiMax Reagent (Life Technologies) according to the manufacturer's instruction.

\section{RNA isolation and quantitative real-time PCR}

Total RNA was extracted using TRIzol reagent (Life Technologies), and cDNA was synthesized using TransScript Reverse Transcriptase (TransGen Biotech). cDNA products were amplified using CFX-96 Touch Real-Time PCR Detection System (BioRad). GAPDH were used as an internal control. mRNA levels were

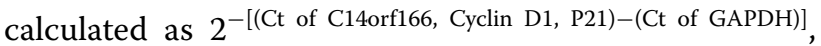
where Ct represents the threshold cycle of each transcript [16]. All experiments were performed in triplicate. The primers selected are as follows: C14orf166: forward 5'TGTTCCGACGCAAGTTGA3' and reverse 
5'CGCTGCTGTGGATGTTTCT3'.Cyclin D1:forward $5^{\prime}$-TCCTCTCCAAAATGCCAGAG- $3^{\prime}$ and reverse $5^{\prime}$-GG CGGATTGGAAATGAACTT-3'. P21:forward 5'-CGAT GCCAACCTCCTCAACGA-3 $3^{\prime}$ and reverse $5^{\prime}$-TCGC AGACCTCCAGCATCCA-3'. GAPDH:forward 5'GGTG GTCTCCTCTGACTTC $3^{\prime}$ and reverse $5^{\prime}$ CTCTTCCTC TTGTGCTCTTG3'.

\section{Western blot and immunohistochemistry (IHC)}

Cells were lysed with $50 \mathrm{mM}$ Tris at $\mathrm{pH} 7.4,150 \mathrm{mM} \mathrm{NaCl}$, 1 mM EDTA, $1 \%$ NP-40, 1 \% TritonX-100 supplemented with protease inhibitors (Complete, Roche). The following antibodies were used: anti-C14orf166 (1:500, 19848-1-AP, Proteintech), anti-Cyclin D1 (1:1000, sc-753, Santa Cruz Biotechnology Inc), anti-P21 (1:500, sc-397, Santa Cruz Biotechnology Inc), anti-P27 (1:1000, sc-528, Santa Cruz Biotechnology Inc), anti-Rb (ab6075, Abcam) and antiphosphorylated $\mathrm{Rb}$ (ab47763, Abcam). The membranes were stripped and re-probed with an anti- $\beta$-actin antibody (1:3000, HC201-02, TransGen Biotech) or anti- $\alpha$-Tubulin antibody (1:1000, AT819, Beyotime) as the loading control.

IHC was performed according to standard methods as described previously [17]. The following antibodies were used: anti-C14orf166 (1:200, 19848-1-AP, Proteintech), anti-ER (1:100, ab16660, Abcam) and anti-PR (1:20, ab2765, Abcam). The results of staining were scored independently by three pathologists blinded to clinical outcome, based on both the proportion of positively stained tumors cells and the intensity of staining. The proportion of tumor cells was scored as follows: Score 0 -no positive cells, Score 1 -up to $10 \%$ positive cells, Score $2-10 \sim 50 \%$ positive cells, Score $3-50-80 \%$ positive cells, Score $4-$ over $80 \%$ positive cells. The intensity of protein expression was shown as follows: 0 (no staining), 1 (weak staining, light yellow), 2 (moderate staining, yellowish brown), and 3 (strong staining, brown).

The staining index (SI) was calculated as the product of the staining intensity and the proportion of positive cell scores (scored as $0,1,2,3,4,6,8,9$ or 12). Cut-off values for C14orf166 expression were chosen based on a measurement of heterogeneity using the log-rank test with respect to overall survival. The optimal cut-off was identified as an SI score of more than or equal to four was considered as having high C14orf166 expression, and a score less than 4 was considered as having C14orf166 expression.

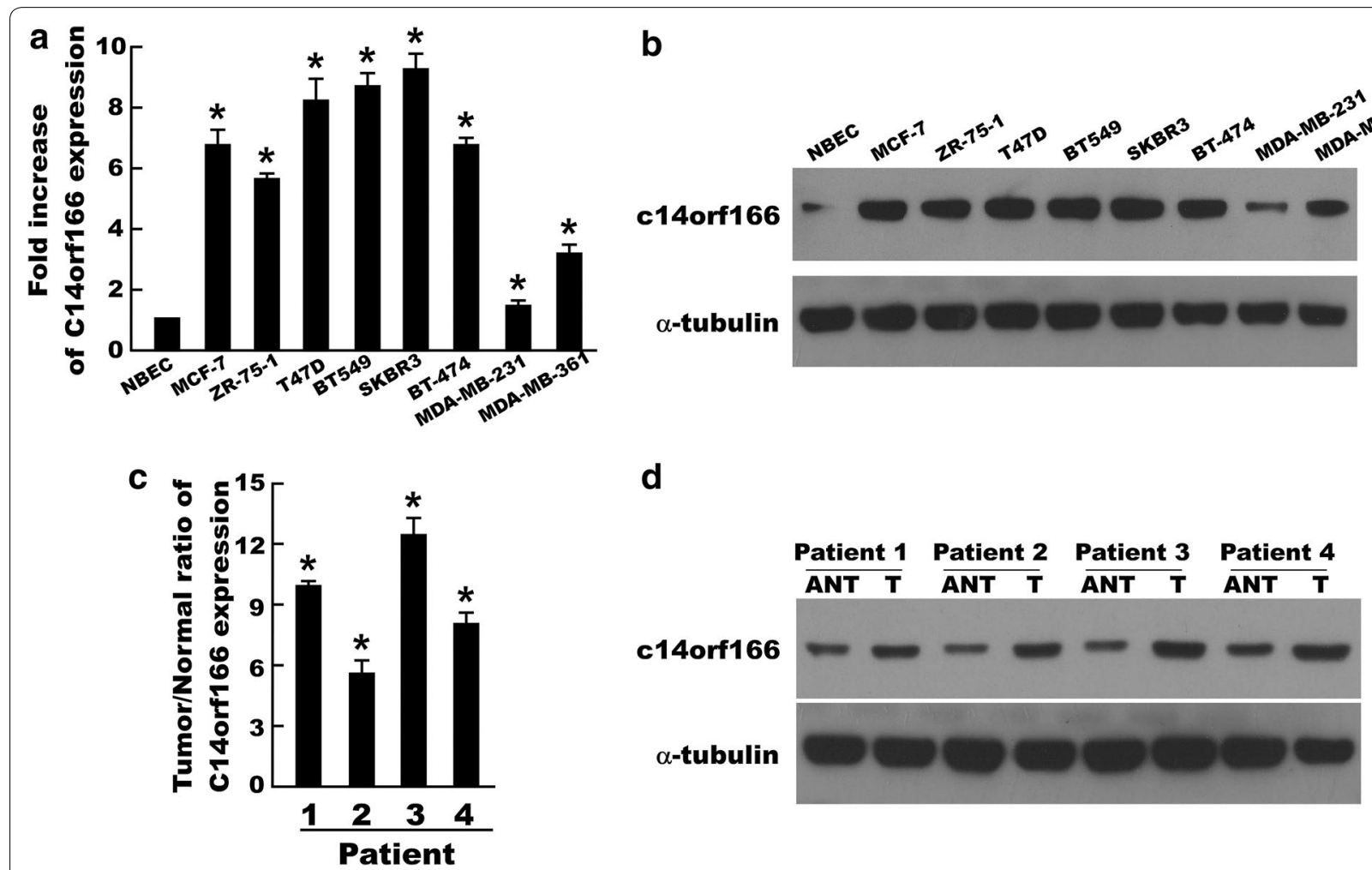

Fig. 1 C14orf166 is upregulated in breast cancer cells and tissues. (a, b) Quantitative real-time PCR and western blot analyzed C14orf166 expression in NBEC and breast cancer cells, including MCF-7, ZR-75-1, T47D, BT549, SKBR3, BT-474, MDA-MB231 and MDA-MB-361. (c, d) Quantitative real-time PCR and western blot analyzed C140rf166 expression in four paired tumor tissues and adjacent normal tissues. Error bars are standard deviation of the mean (SD) calculated from three experiments performed in parallel, ${ }^{*} p<0.05$ 


\section{MTT assay}

MTT assay was performed as described previously [18].

\section{Colony formation assay}

Colony formation assay was performed as described previously [19].

\section{Statistical analysis}

All statistical analyses were carried out by the SPSS version 19.0 software (SPSS, Chicago, IL., USA). The Chisquare test was used to analyze the correlation between C14orf166 expression and clinicopathological characteristics. Bivariate correlations between variables were calculated by Pearson's correlation coefficient. Survival curve was plotted using Kaplan-Meier survival analysis and compared by the log-rank test. Univariate and multivariate Cox regression analyses were used to estimate the significance of various variables for survival. Results are presented as mean \pm SD for at least three independent experiments, cell proliferation assay were tested using Student's $t$ test (two-tailed) for independent samples. $\mathrm{p}<0.05$ in all cases was considered significant.

\section{Results}

C140rf166 is upregulated in breast cancer cells and tissues To investigate the role of C14orf166 in breast cancer, we first demonstrated C14orf166 expression in NBEC and breast cancer cells. Quantitative real-time PCR and western blot assay found C14orf166 expression was significantly upregulated in breast cancer cells compared to NBEC (Fig. 1a, b). To investigate whether C14orf166 was also upregulated in breast cancer tissues, we determined C14orf166 expression in four paired tumor tissues (T) and matched adjacent normal tissues (ANT), quantitative real-time PCR and western blot assay showed C14orf166 also was upregulated in breast cancer tissues compared to adjacent noncancerous tissues (Fig. 1c, d).

\section{C14orf166 overexpression is associated with clinical progression of breast cancer}

We used IHC to determine C14orf166 expression in 121 paraffin-embedded, archival breast cancer tissues, including 15 stageI tumors, 55 stage II tumors, 34 stage III tumors, 17 stage IV tumors. C14orf166 was high expression in 63 (52.1\%) cases, and no or low expression in the remaining $58(47.9 \%)$ cases (Table 1$)$. The positive rate increased with advancing clinical stage as follows: $13.3 \%$ for stage I $(2 / 15), 43.6 \%$ for stage II $(24 / 55)$, $67.6 \%$ for stage III (23/34), $82.4 \%$ for stage IV (14/17) (Table 1). IHC assay shown that C14orf166 was primarily localized in the tumor cell nuclei (Fig. 2), and its expression was positively correlated with advancing clinical stage (Fig. 2), Taken together, these results suggested
Table 1 Correlation between C14orf166 expression and clinicopathologic characteristics of breast cancer patient

\begin{tabular}{|c|c|c|c|c|}
\hline \multirow{2}{*}{$\begin{array}{l}\text { Character- } \\
\text { istics }\end{array}$} & \multirow{2}{*}{ Total } & \multicolumn{2}{|l|}{ C14orf166 } & \multirow{2}{*}{$\begin{array}{l}\text { Chi-square } \\
\text { test } p \text { value }\end{array}$} \\
\hline & & $\begin{array}{l}\text { Low } \\
\text { expression }\end{array}$ & $\begin{array}{l}\text { High } \\
\text { expression }\end{array}$ & \\
\hline \multicolumn{5}{|l|}{ Age (years) } \\
\hline$<40$ & 27 & 12 & 15 & \multirow[t]{2}{*}{0.424} \\
\hline$\geq 40$ & 94 & 46 & 48 & \\
\hline \multicolumn{5}{|c|}{ Clinical stage } \\
\hline I & 15 & 13 & 2 & \multirow[t]{4}{*}{$<0.001$} \\
\hline ॥ & 55 & 31 & 24 & \\
\hline III & 34 & 11 & 23 & \\
\hline IV & 17 & 3 & 14 & \\
\hline \multicolumn{5}{|c|}{ T classification } \\
\hline $\mathrm{T}_{1}$ & 26 & 17 & 9 & \multirow[t]{4}{*}{$<0.01$} \\
\hline $\mathrm{T}_{2}$ & 65 & 34 & 31 & \\
\hline $\mathrm{T}_{3}$ & 23 & 6 & 17 & \\
\hline $\mathrm{T}_{4}$ & 7 & 1 & 6 & \\
\hline \multicolumn{5}{|c|}{ N classification } \\
\hline 0 & 45 & 33 & 21 & \multirow[t]{4}{*}{$<0.001$} \\
\hline 1 & 48 & 18 & 30 & \\
\hline 2 & 25 & 6 & 19 & \\
\hline 3 & 3 & 1 & 2 & \\
\hline \multicolumn{5}{|c|}{ M classification } \\
\hline Yes & 6 & 0 & 6 & \multirow[t]{2}{*}{0.018} \\
\hline No & 115 & 58 & 57 & \\
\hline \multicolumn{5}{|l|}{ ER } \\
\hline 0 & 51 & 23 & 28 & \multirow[t]{4}{*}{0.325} \\
\hline 1 & 58 & 28 & 30 & \\
\hline 2 & 9 & 4 & 5 & \\
\hline 3 & 3 & 3 & 0 & \\
\hline \multicolumn{5}{|l|}{ PR } \\
\hline 0 & 49 & 18 & 31 & \multirow[t]{5}{*}{0.02} \\
\hline 1 & 60 & 30 & 30 & \\
\hline 2 & 10 & 9 & 1 & \\
\hline 3 & 1 & 0 & 1 & \\
\hline 4 & 1 & 1 & 0 & \\
\hline \multicolumn{5}{|c|}{ Vital status (at follow-up) } \\
\hline Alive & 64 & 51 & 13 & \multirow[t]{2}{*}{$<0.001$} \\
\hline Dead & 57 & 7 & 50 & \\
\hline
\end{tabular}

C14orf166 expression increased with advancing clinical stage in breast cancer.

We examined the relationship between C14orf166 expression and clinicopathological characteristics using Chi-square test, As presented in Table 2, we revealed that high C14orf166 expression was significantly correlated with advanced clinical stage $(\mathrm{p}<0.001)$, T classification (larger tumor size, $\mathrm{p}<0.01$ ), $\mathrm{N}$ classification (lymph node involvement, $\mathrm{p}<0.001$ ), M classification 


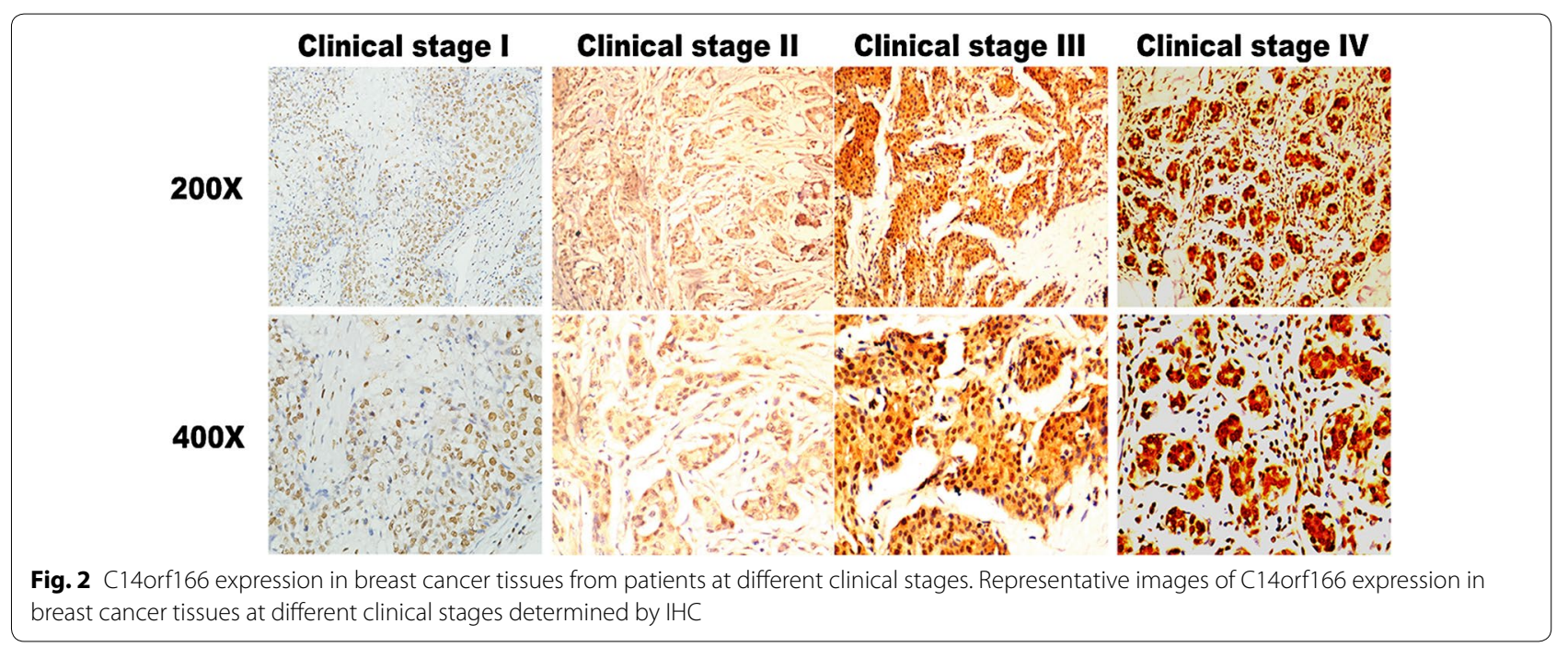

Table 2 Spearman analysis of correlation between C14orf166 and clinicopathological characteristics

\begin{tabular}{lcr}
\hline Variables & \multicolumn{2}{c}{ C14orf166 expression level } \\
\cline { 2 - 3 } & Spearman correlation & $\boldsymbol{p}$ Value \\
\hline Survival time & -0.735 & $<0.001$ \\
Vital status & 0.674 & $<0.001$ \\
Age & -0.037 & 0.684 \\
ER & -0.068 & 0.280 \\
PR & -0.236 & 0.009 \\
Clinical stage & 0.404 & $<0.001$ \\
T classification & 0.295 & 0.001 \\
N classification & 0.390 & $<0.001$ \\
M classification & 0.088 & 0.270 \\
\hline
\end{tabular}

(distant metastasis, $\mathrm{p}=0.018), \mathrm{PR}(\mathrm{p}=0.02)$ and vital status $(\mathrm{p}<0.001)$. But there were no statistically correlations between C14orf166 expression and age and ER. The correlations between C14orf166 and the clinicopathological characteristics were further confirmed used Spearman's correlation analysis, as shown in Table 2, C14orf166 expression were significantly correlated with survival time $(\mathrm{p}<0.001)$, vital status $(\mathrm{p}<0.001)$, advancing clinical stage $(\mathrm{p}<0.001)$, $\mathrm{T}$ classification $(\mathrm{p}=0.001)$, $\mathrm{N}$ classification $(\mathrm{p}<0.001)$ and PR $(\mathrm{p}=0.009)$. There weren't significance correlations between C14orf166 expression and age and ER. But distant metastasis which significantly correlated with C14orf166 expression used Chi-square test had not significance correlation with C14orf166 expression used Spearman's correlation analysis. These results suggested C14orf166 expression was positively correlated with and advanced clinical stage, $\mathrm{T}$ classification, $\mathrm{N}$ classification, PR and vital status.

\section{C14orf166 is a poor prognostic factor for patients with breast cancer}

Kaplan-Meier survival analysis and the log-rank test demonstrated that the overall survival of the patients with high C14orf166 expression was significantly shorter than those with low C14orf166 expression (Fig. 3a). Univariate Cox regression analysis showed that C14orf166 expression $(\mathrm{p}<0.001)$, clinical stage $(\mathrm{p}=0.013)$, T classification $(\mathrm{p}<0.001)$ and $\mathrm{N}$ classification $(\mathrm{p}=0.007)$ were unfavorable prognostic factors (Table 3 ). To determine whether C14orf166 expression is an independent prognostic factor of outcomes, multivariate survival analysis revealed C14orf166 expression, clinical stage, $\mathrm{T}$ classification and $\mathrm{N}$ classification were recognized as independent prognostic factors for patients with breast cancer (Table 3).

Additionally, we analyzed the prognostic value of C14orf166 expression in selective subgroups of breast cancer patients stratified according to clinical stage. Patients with tumors exhibiting high C14orf166 expression had significantly shorter overall survival than those with low C14orf166 expression in the clinical stage III subgroup (Fig. 3b, p < 0.05) and clinical stage III-IV subgroup (Fig. 3c, p < 0.05). These suggested C14orf166 was a valuable prognostic factor for patients with breast cancer.

\section{C14orf166 contributes to cell proliferation of breast cancer}

To explore the role of C14orf166 in the progression of breast cancer cells, we overexpressed C14or166 in breast cancer cells ZR-75-1 and MDA-MB361 to determine its effect on cell proliferation, MTT analysis found C14orf166 overexpression increased proliferation rate of breast cancer cells (Fig. 4a), colony formation assay 


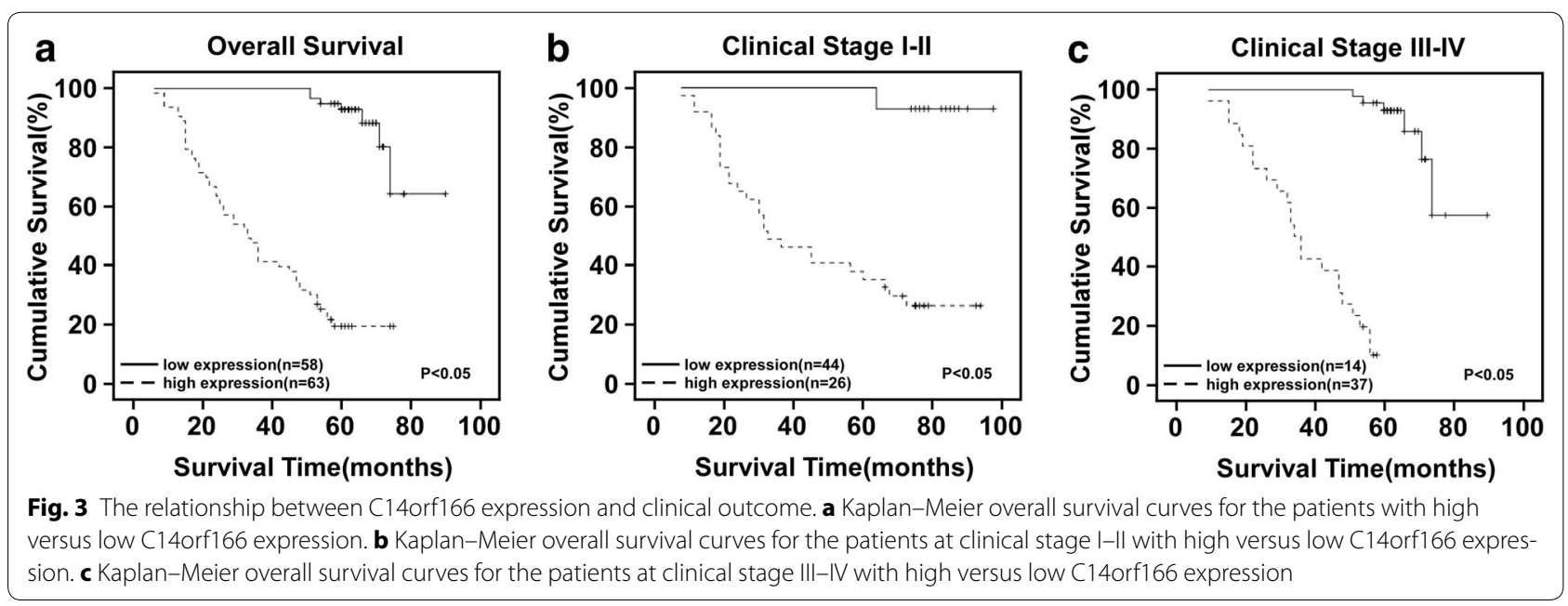

Table 3 Univariate and multivariate analyses of various prognostic parameters in patients with liver cancer Cox-regression analysis

\begin{tabular}{|c|c|c|c|c|c|c|}
\hline & \multicolumn{3}{|c|}{ Univariate analysis } & \multicolumn{3}{|c|}{ Multivariate analysis } \\
\hline & No. patients & $p$ & $\begin{array}{l}\text { Regression coefficient } \\
\text { (SE) }\end{array}$ & $p$ & Relative risk & $\begin{array}{l}95 \% \text { Confidence } \\
\text { interval }\end{array}$ \\
\hline C14orf166 & & $<0.001$ & $2.678(0.412)$ & $<0.001$ & 15.231 & $6.472-35.847$ \\
\hline Low expression & 58 & & & & & \\
\hline High expression & 63 & & & & & \\
\hline Clinical stage & & 0.013 & $0.363(0.145)$ & 0.044 & 0.702 & $0.498-0.990$ \\
\hline 1 & 15 & & & & & \\
\hline$\|$ & 55 & & & & & \\
\hline III & 37 & & & & & \\
\hline IV & 17 & & & & & \\
\hline T classification & & $<0.001$ & $0.623(0.170)$ & 0.007 & 1.705 & $1.156-2.516$ \\
\hline $\mathrm{T}_{1}$ & 26 & & & & & \\
\hline $\begin{array}{l}T_{2} \\
T_{3}\end{array}$ & 65 & & & & & \\
\hline$T_{3}$ & 23 & & & & & \\
\hline $\mathrm{T}_{4}$ & 7 & & & & & \\
\hline N classification & & 0.007 & $0.389(0.145)$ & 0.001 & 4.598 & $1.878-11.256$ \\
\hline 0 & 45 & & & & & \\
\hline 1 & 48 & & & & & \\
\hline 2 & 25 & & & & & \\
\hline 3 & 3 & & & & & \\
\hline
\end{tabular}

suggested C14orf166 overexpression significantly promoted proliferation of breast cancer cells (Fig. 4b). To further examined the effect of C14orff166 on cell proliferation, we downregulated C14orf166 used small inference RNA (siRNA), MTT analysis found knockdown of C14orf166 reduced proliferation rate of breast cancer cells (Fig. 4a), colony formation assay confirmed that C14orf166 knockdown significantly inhibited proliferation of breast cancer cells (Fig. 4b). Taken together, these results suggested C14orf166 regulated the proliferation of breast cancer cells.

Cell proliferation is regulated by many key cell cycle regulatory proteins, including $\mathrm{P} 21, \mathrm{P} 27$, Cyclin D1, Rb and the phosphorylation level of $\mathrm{Rb}$. These proteins play critical role in G1/S transition. We investigated their levels by modulating C14orf166 expression. Quantitative real-time PCR assay found when C14orf166 was overexpressed in indicated breast cancer cells, P21 and P27 


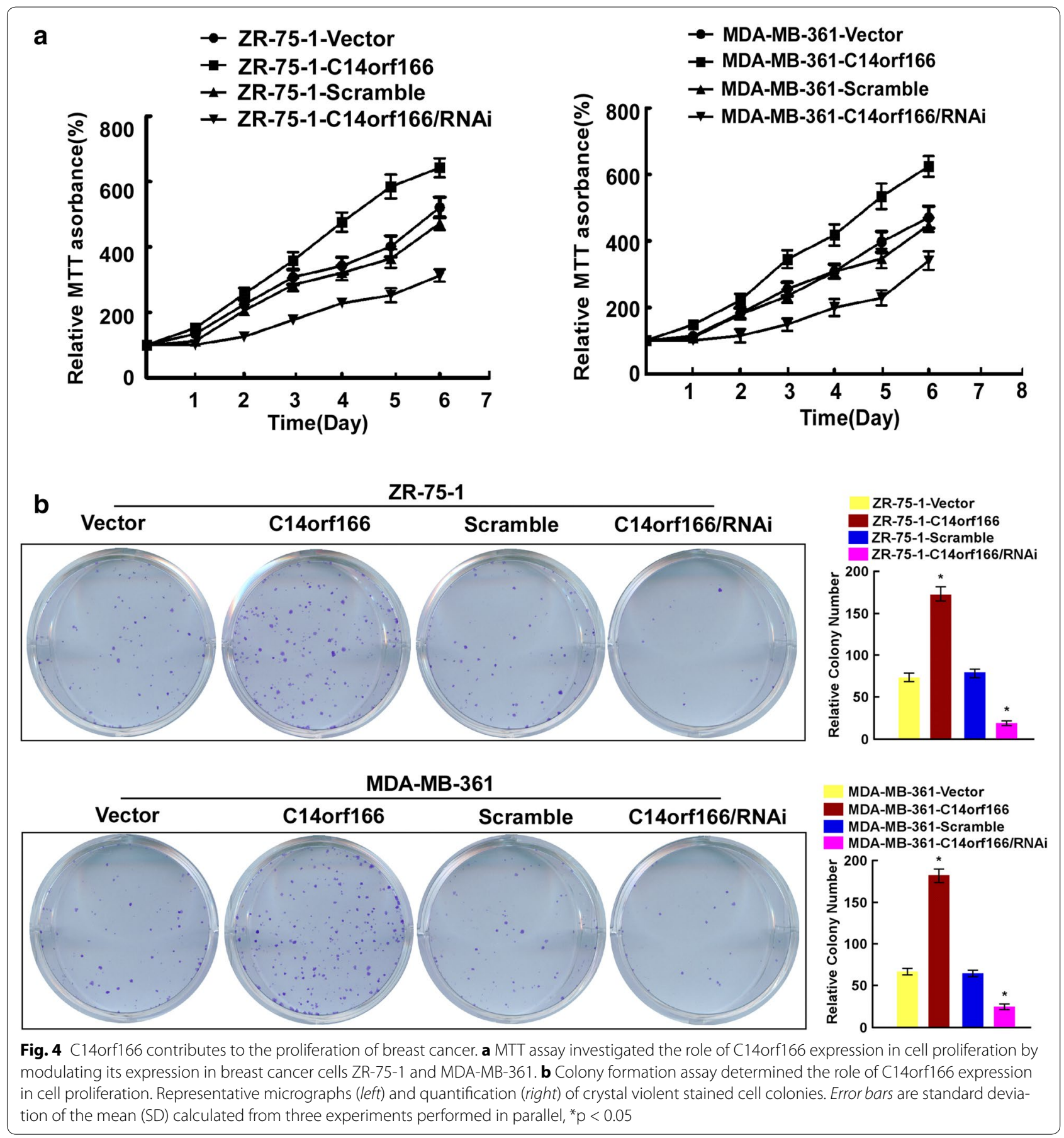

were upregulated, when C14orf166 was downregulated, P12 and P27 were downregulated (Fig. 5a). Western blot showed that Cyclin D1 and the phosphorylation level of $\mathrm{Rb}$ were decreased, P21 and P27 were increased, Rb was not changed, when C14orf166 was overexpressed. Cyclin D1 and the phosphorylation level of $\mathrm{Rb}$ were increased, P21 and P27 were decreased, when C14orf166 was downregulated (Fig. 5b). These suggested C14orf166 promoted cell proliferation by accelerating G1/S transition. We have found C14orf166 expression was correlated with $\mathrm{T}$ classification, the results investigated from breast cancer cells also found C14orf166 promoted cell proliferation. Results from clinic and cells were consistent. 


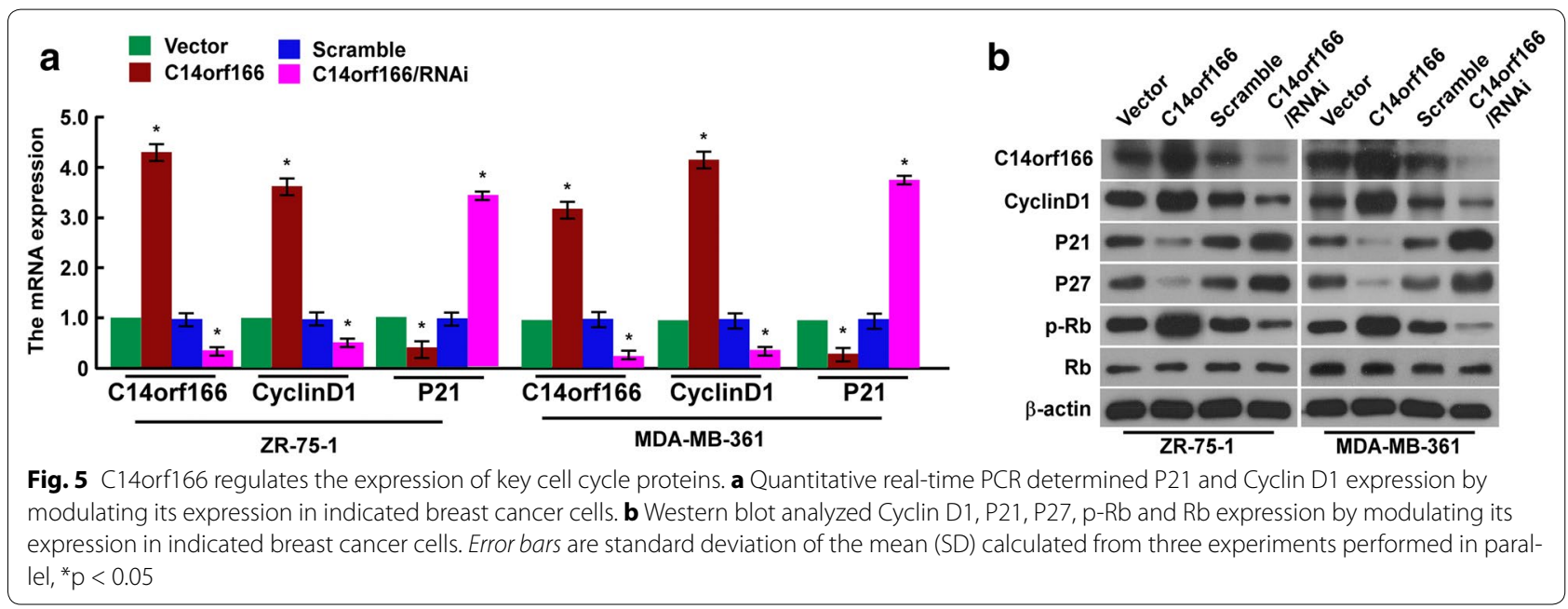

\section{Discussion}

In our current studies, we revealed C14orf166 was overexpressed in breast cancer cells and tissues, it might be a novel oncogene, we further analyzed C14orf166 expression in a cohort of 121 samples by IHC, and investigated the correlation between C14orf166 expression and clinicopathological characteristics. Statistical analyses suggested C14orf166 expression was increased with advancing clinical stage, and had significance correlation with advanced clinical stage, $\mathrm{T}$ classification, $\mathrm{N}$ classification, PR and vital status. Patients with high C14orf166 expression had shorter survival than those with low C14orf166 expression. C14orf166 could serve as a valuable prognostic factor. We also determined the role of C14orf166 in cellular proliferation, and found overexpression of C14orf166 promoted cellular proliferation, knockdown of C14orf166 inhibited cellular proliferation. Mechanism analysis revealed C14orf166 promoted cell proliferation by accelerating G1/S transition.

Centrosomal protein ninein interacts with glycogen synthase kinase 3beta (GSK-3 $\beta$ ), and be phosphorylated by GSK-3 $\beta$ [20]. The activity of Janus kinase 2 (JAK2) is inhibited by ninein [21], constitutive activation of JAK2/ STAT5 promotes resistance to apoptosis and contributes to tumorigenesis of breast cancer [22], these suggest ninein may inhibit the development and progression of breast cancer. C14orf166 interacts with ninein to block the phosphorylation of ninein catalyzed by GSK-3 $\beta$ [13], suggesting C14orf166 may inhibit ninein, and activate JAK2 to promote breast cancer progression, but this speculation remain to be confirmation. The regulation mechanism of C14orf166 is still to be explored. JAK2/STAT3 promotes self-renewal of breast cancer stem cells, $\mathrm{CD} 24^{-} \mathrm{CD} 44^{+}$is a marker for breast cancer stem cells $[23,24]$. Activation of JAK2/STAT3 pathway preferentially promotes the self-renewal of $\mathrm{C} 24^{-} \mathrm{CD} 44^{+}$ breast cancer stem cells [25]. It reveals that C14orf166 may promote self-renewal of breast cancer stem cells.

Yazhou Cui et, al. find C14orf166 is higher expression in pancreatic cancer with lymph node metastasis than that of in pancreatic cancer without lymph node metastasis by difference gel electrophoresis, they speculate C14orf166 could be a novel metastasis-associated protein [26]. In our study, we found there was a correlation between C14orf166 expression and lymph node metastasis, it was aggressed with previous report. But there wasn't a correlation between C14orf166 expression and distant metastasis. The different results may cause by different kinds of tumors. However, our findings still need to be replicated, and further investigation used more patients' tissues is required to verify these hypotheses.

\section{Conclusions}

In summary, our research show that C14orf166 is an unfavorable prognostic factor for breast cancer patients, patients with high C14orf166 expression have shorter survival than those with low C14orf166 expression. C14orf166 accelerates G1/S transition and promotes proliferation of breast cancer cell.

\section{Additional file}

Additional file 1: Table S1. Clinicopathological characteristics of patient samples and expression of C14orf166 in breast cancer.

\section{Authors' contributions}

LHP, WSM, CTY, ZHY and CW designed the experiments. CTY, ZHY, CW, ZB, LLS and YJY performed the experiments. LHP, WSM, CTY, ZHY and CW analyzed the data. CTY, ZB, LLS and YJY collected clinical samples and interpreted clinical data. ZHY and CW performed cell proliferation analysis. LHP and WSM wrote the manuscript. All authors read and approved the final manuscript. 


\section{Author details}

${ }^{1}$ Department of Thyroid and Breast Surgery, The First Affiliated Hospital of Sun Yat-sen University, 510080 Guangzhou, People's Republic of China. ${ }^{2}$ Department of Neurological Intensive Care Unit, The First Affiliated Hospital of Sun Yat-sen University, 510080 Guangzhou, People's Republic of China. ${ }^{3}$ Department of Medical Imaging, The First Affiliated Hospital of Sun Yat-sen University, 510080 Guangzhou, People's Republic of China. ${ }^{4}$ Department of Medical Oncology, The First Affiliated Hospital of Sun Yat-sen University, 510080 Guangzhou, People's Republic of China.

\section{Acknowledgements}

This work was supported by National Natural Science Foundation of China (No. 30600156), National Natural Science Foundation of China (No. 81270378), National Natural Science Foundation of China (No. 81372821), Natural Science Foundation of Guangdong Province (No. 2014A030313090), Natural Science Foundation of Guangdong Province (No. 2014A030313190), Science and Technology Projects Foundation of Guangdong Province (No. 2015A070710006) and Science and Technology Projects Foundation of Guangzhou City (No. 201507020037).

\section{Competing interests}

The authors declare that they have no competing interests.

Received: 9 October 2015 Accepted: 27 January 2016 Published online: 17 February 2016

\section{References}

1. Wu J, Liu S, Liu G, Dombkowski A, Abrams J, Martin-Trevino R, Wicha MS, Ethier SP, Yang ZQ. Identification and functional analysis of 9p24 amplified genes in human breast cancer. Oncogene. 2012;31(3):333-41. doi:10.1038/onc.2011.227.

2. Pece S, Tosoni D, Confalonieri S, Mazzarol G, Vecchi M, Ronzoni S, Bernard L, Viale G, Pelicci PG, Di Fiore PP. Biological and molecular heterogeneity of breast cancers correlates with their cancer stem cell content. Cell. 2010;140(1):62-73. doi:10.1016/j.cell.2009.12.007.

3. Neve RM, Chin K, Fridlyand J, Yeh J, Baehner FL, Fevr T, Clark L, Bayani N, Coppe JP, Tong F, Speed T, Spellman PT, DeVries S, Lapuk A, Wang NJ, Kuo WL, Stilwell JL, Pinkel D, Albertson DG, Waldman FM, McCormick F, Dickson RB, Johnson MD, Lippman M, Ethier S, Gazdar A, Gray JW. A collection of breast cancer cell lines for the study of functionally distinct cancer subtypes. Cancer Cell. 2006;10(6):515-27. doi:10.1016/j.ccr.2006.10.008.

4. Burstein HJ, Elias AD, Rugo HS, Cobleigh MA, Wolff AC, Eisenberg PD, Lehman M, Adams BJ, Bello CL, DePrimo SE, Baum CM, Miller KD. Phase II study of sunitinib malate, an oral multitargeted tyrosine kinase inhibitor, in patients with metastatic breast cancer previously treated with an anthracycline and a taxane. J Clin Oncol: Off J Am Soc Clin Oncol. 2008;26(11):1810-6. doi:10.1200/JCO.2007.14.5375.

5. Hayes DF. Bevacizumab treatment for solid tumors: boon or bust? JAMA. 2011;305(5):506-8. doi:10.1001/jama.2011.57.

6. Goldenberg MM. Trastuzumab, a recombinant DNA-derived humanized monoclonal antibody, a novel agent for the treatment of metastatic breast cancer. Clin Ther. 1999;21(2):309-18. doi:10.1016/ S0149-2918(00)88288-0.

7. Korkaya H, Kim Gl, Davis A, Malik F, Henry NL, Ithimakin S, Quraishi AA, Tawakkol N, D'Angelo R, Paulson AK, Chung S, Luther T, Paholak HJ, Liu S, Hassan KA, Zen Q, Clouthier SG, Wicha MS. Activation of an IL6 inflammatory loop mediates trastuzumab resistance in HER2 + breast cancer by expanding the cancer stem cell population. Mol Cell. 2012;47(4):570-84. doi:10.1016/j.molcel.2012.06.014.

8. Huarte M, Sanz-Ezquerro JJ, Roncal F, Ortin J, Nieto A. PA subunit from influenza virus polymerase complex interacts with a cellular protein with homology to a family of transcriptional activators. J Virol. 2001;75(18):8597-604.

9. Perez-Gonzalez A, Rodriguez A, Huarte M, Salanueva IJ, Nieto A. hCLE/ CGI-99, a human protein that interacts with the influenza virus polymerase, is a mRNA transcription modulator. J Mol Biol. 2006;362(5):887-900. doi:10.1016/j.jmb.2006.07.085.
10. Lee JW, Liao PC, Young KC, Chang CL, Chen SS, Chang TT, Lai MD, Wang SW. Identification of hnRNPH1, NF45, and C14orf166 as novel host interacting partners of the mature hepatitis C virus core protein. J Proteome Res. 2011;10(10):4522-34. doi:10.1021/pr200338d.

11. Perez-Gonzalez A, Pazo A, Navajas R, Ciordia S, Rodriguez-Frandsen A, Nieto A. hCLE/C14orf166 associates with DDX1-HSPC117-FAM98B in a novel transcription-dependent shuttling RNA-transporting complex. PLoS One. 2014;9(3):e90957. doi:10.1371/journal.pone.0090957.

12. Ou YY, Mack GJ, Zhang M, Rattner JB. CEP1 10 and ninein are located in a specific domain of the centrosome associated with centrosome maturation. J Cell Sci. 2002;115(Pt 9):1825-35.

13. Howng SL, Hsu HC, Cheng TS, Lee YL, Chang LK, Lu PJ, Hong YR. A novel ninein-interaction protein, CGl-99, blocks ninein phosphorylation by GSK3beta and is highly expressed in brain tumors. FEBS Lett. 2004;566(13):162-8. doi:10.1016/j.febslet.2004.04.024.

14. Yang L, Li F, Lei F, Wang Y, Wu S, Song L, Chen Y. Overexpression of chromosome 14 open reading frame 166 correlates with disease progression and poorer prognosis in human NPC. Tumour Biol : J Int Soc Onco Dev Biol Med. 2015. doi:10.1007/s13277-015-3518-8.

15. Guo J, Wang W, Liao P, Lou W, Ji Y, Zhang C, Wu J, Zhang S. Identification of serum biomarkers for pancreatic adenocarcinoma by proteomic analysis. Cancer Sci. 2009;100(12):2292-301. doi:10.1111/j.1349-7006.2009.01324.x.

16. Livak KJ, Schmittgen TD. Analysis of relative gene expression data using real-time quantitative PCR and the 2(-Delta Delta C(T)) Method. Methods. 2001;25(4):402-8. doi:10.1006/meth.2001.1262.

17. Guo BH, Feng Y, Zhang R, Xu LH, Li MZ, Kung HF, Song LB, Zeng MS. Bmi-1 promotes invasion and metastasis, and its elevated expression is correlated with an advanced stage of breast cancer. Mol cancer. 2011;10(1):10. doi:10.1186/1476-4598-10-10.

18. Liu S, Patel SH, Ginestier C, Ibarra I, Martin-Trevino R, Bai S, McDermott SP, Shang L, Ke J, Ou SJ, Heath A, Zhang KJ, Korkaya H, Clouthier SG, CharafeJauffret E, Birnbaum D, Hannon GJ, Wicha MS. MicroRNA93 regulates proliferation and differentiation of normal and malignant breast stem cells. PLoS Genet. 2012;8(6):e1002751. doi:10.1371/journal.pgen.1002751.

19. Zhang Y, Huang W, Ran Y, Xiong Y, Zhong Z, Fan X, Wang Z, Ye Q. miR582-5p inhibits proliferation of hepatocellular carcinoma by targeting CDK1 and AKT3. Tumour Biol : J Int Soc Onco Dev Biol Med. 2015. doi:10.1007/s13277-015-3582-0.

20. Hong YR, Chen CH, Chang JH, Wang S, Sy WD, Chou CK, Howng SL. Cloning and characterization of a novel human ninein protein that interacts with the glycogen synthase kinase 3beta. Biochim Biophys Acta. 2000;1492(2-3):513-6.

21. Jay J, Hammer A, Nestor-Kalinoski A, Diakonova M. JAK2 tyrosine kinase phosphorylates and is negatively regulated by centrosomal protein Ninein. Mol Cell Biol. 2015;35(1):111-31. doi:10.1128/MCB.01138-14.

22. Caffarel MM, Zaragoza R, Pensa S, Li J, Green AR, Watson CJ. Constitutive activation of JAK2 in mammary epithelium elevates Stat5 signalling, promotes alveologenesis and resistance to cell death, and contributes to tumourigenesis. Cell Death Differ. 2012;19(3):511-22. doi:10.1038/ cdd.2011.122

23. Ke J, Zhao Z, Hong SH, Bai S, He Z, Malik F, Xu J, Zhou L, Chen W, MartinTrevino R, Wu X, Lan P, Yi Y, Ginestier C, Ibarra I, Shang L, McDermott S, Luther T, Clouthier SG, Wicha MS, Liu S. Role of microRNA221 in regulating normal mammary epithelial hierarchy and breast cancer stem-like cells. Oncotarget. 2015;6(6):3709-21.

24. Nakshatri H, Srour EF, Badve S. Breast cancer stem cells and intrinsic subtypes: controversies rage on. Curr Stem Cell Res Ther. 2009;4(1):50-60.

25. Marotta LL, Almendro V, Marusyk A, Shipitsin M, Schemme J, Walker SR, Bloushtain-Qimron N, Kim JJ, Choudhury SA, Maruyama R, Wu Z, Gonen M, Mulvey LA, Bessarabova MO, Huh SJ, Silver SJ, Kim SY, Park SY, Lee HE, Anderson KS, Richardson AL, Nikolskaya T, Nikolsky Y, Liu XS, Root DE, Hahn WC, Frank DA, Polyak K. The JAK2/STAT3 signaling pathway is required for growth of CD44(+)CD24(-) stem cell-like breast cancer cells in human tumors. J Clin Investig. 2011;121(7):2723-35. doi:10.1172/ $\mathrm{JCl} 44745$.

26. Cui Y, Wu J, Zong M, Song G, Jia Q, Jiang J, Han J. Proteomic profiling in pancreatic cancer with and without lymph node metastasis. Int J Cancer J Du Int Cancer. 2009;124(7):1614-21. doi:10.1002/ijc.24163. 